\title{
Parramedicine *
}

\section{Commentary}

\section{Pandemic pupils: COVID-19 and the impact on student paramedics}

Andre Perkins is a paramedicine student ${ }^{1}$; Sarah Kelly is a paramedicine student ${ }^{1}$; Hannah Dumbleton is a paramedicine student'; Steve Whitfield RP, RGS, FAWM, WEMT is Lecturer and Course Convenor in Paramedicine ${ }^{1}$

\section{Affiliation:}

${ }^{1}$ Griffith University, School of Medicine, Queensland

https://doi.org/10.33151/ajp.17.811

\section{Abstract}

The COVID-19 pandemic is having a profound effect on the learning of student paramedics. This commentary aims to explores how student paramedics have been affected by COVID-19 and seeks to identify the perceived impact of this experience.

\section{Keywords:}

student paramedic; pandemic; ambulance service; paramedic education

Corresponding Author: Steve Whitfield, s.whitfield@griffith.edu.au 


\section{Introduction}

The new coronavirus disease COVID-19 has spread to almost every country in the world (1). It has caused global community, education and industry shutdowns of which the true impact is only just emerging. The tremendous impact on education worldwide is being monitored by the United Nations Educational, Scientific and Cultural Organization who estimate that as at 23 April 2020 approximately 1.579 billion learners globally have been affected by closures of education facilities, amounting to $90.2 \%$ of the world's student population (2).

For student paramedics, the COVID-19 pandemic is having a profound effect. It has shifted lectures and tutorials to online learning platforms and has caused the suspension of practical sessions and all forms of clinical placement.

We set out to explore how student paramedics have been affected by the COVID-19 pandemic holistically and sought to identify the perceived impact from this experience.

\section{Teaching and learning}

On campus, face-to-face practical sessions are a vital resource for student paramedics where learning occurs through student experiences. Educators facilitate these experiences through building an environment in which students can interact, engage and learn (3). Due to the high level of practical clinical skills and procedures in paramedicine, shifting paramedicine to online learning is inherently challenging for students who need to acquire experience and knowledge of practical skills. The inability to attend lectures, tutorials and practicals in person disrupts the normal student paramedic learning routine.

Although every student is different, many students prefer to study on campus and many students express that studying at home is distractive (4). Hence, online learning at home may well be proving difficult for some student paramedics where this disruption of routine is requiring them to potentially employ more cognitive willpower to attend and engage in online learning sessions. A 2018 study demonstrated healthcare students felt they greatly benefitted from doing real-time scenarios and receiving constructive feedback from classmates and academic staff in practical sessions (5). A lack of these face-to-face practical sessions presents a learning disruption to the development of student paramedics. Moreover, as many students in the health and medical programs are visual and kinaesthetic learners (6), the 'hands-on' element of practical sessions assists greatly in consolidating theoretical knowledge and developing a systematic approach and patient management processes.

Despite this, and the challenges the COVID-19 pandemic poses, this unprecedented period is also providing student paramedics new opportunities for growth. For example, students are now engaging in online practical sessions that lack the 'hands-on' element but increase the difficultly of case management. Students are being asked to explore and manage simulated cases in real-time during online collaborative sessions that ultimately force them to listen, explore and understand the cases at a macro level. This can enhance and develop abilities in patient assessment and management considerations. Online learning also gives student paramedics additional time to consolidate the relevant theoretical information required to understand clinical concepts and explore the intricacies of course content.

\section{Connectiveness and community}

The social aspect of university life has been drastically affected by the COVID-19 pandemic. The sense of community that is developed at university is vital in providing a sense of connectedness for both new and continuing students (7). Creating a positive environment built around collaborative group-focussed learning similar to the high levels of teamwork required in paramedicine is vital for student paramedics as they progress through their learning journey (8). The ability to interact with each other in practical sessions and simulations provides the chance to form strong bonds with peers, ultimately creating a more workforce-ready cohort of students.

This is particularly important for first-year undergraduates who may be experiencing university life for the first time. However, due to social distancing measures and the transition to online learning for all university courses, the prospect of formulating a strong community has been greatly affected. The lack of in-person interaction and ability to gain feedback on clinical skills has led some students to feel isolated and anxious. This not only has a potential adverse effect on the mental health of students but may also be detrimental to their academic performance (9).

However, although the ability to build face-to-face friendships has been altered, the possibility for students to connect online has increased dramatically. Online learning platforms, collaborative mediums and social media have not only enabled cross-course collaboration between student paramedics and other degree programs, it has encouraged this to occur. These social online conversations enable students to connect with others who are in similar situations, maintain some community and course connectiveness, and may enable the formation of new friendships across different academic disciplines (10). The ability for student paramedics to remain connected online is of the utmost importance while the duration of COVID-19 social isolation remains unspecified.

\section{Placements and employment}

Moving beyond COVID-19's impact on learning, its impact on future clinical placements, employment and work readiness is equally recognised. Clinical placements offer an opportunity for student paramedics to gain valuable experience while supervised by qualified paramedics and other healthcare providers. The increased risk to the healthcare workforce, and the students being defined as non-essential personnel in Australia, ultimately resulted in early 2020 placements, both 
domestic and abroad, being cancelled. Although troublesome to the professional development of student paramedics, the unprecedented increase in demand for healthcare associated services has led to many unique employment opportunities for recent graduate paramedics. St Vincent's Hospital in Melbourne, Victoria, openly recruited gradate paramedics to fill roles within the emergency department (11). However, with excessive pressure on the health system, many final-year students are faced with postponed placements and possible delayed graduation.

In Australia, the Australian Health Practitioner Regulation Agency require a specified standard for all healthcare professionals, and it is therefore expected that students will still meet these requirements before they graduate and are eligible to be registered and subsequently work in the healthcare setting (12). Therefore, novel approaches are now required that will demonstrate the achieved outcomes without clinical placement occurring. While the challenges caused by COVID-19 to student paramedics are dynamic and demanding, so too is the paramedicine environment where the need to be able to rapidly adapt to changing situations is vital, and this is currently being instilled in paramedic students.

The COVID-19 pandemic has also seen state services such as the Queensland Ambulance Service and Ambulance Victoria fast-track graduate programs and employ additional paramedics to bolster the workforce in preparation for an influx of people seeking healthcare support $(14,15)$. Although this has presented an opportunity for graduates and graduating students, the repercussions of potential overstaffing as a result of fast-tracking and additional employment are unknown. Jurisdictional ambulance recruitment may be reduced in the next few years, potentially impacting on student paramedics who are yet to graduate.

\section{Conclusion}

The COVID-19 pandemic has and will continue to effect student paramedics as they endeavour in their journey to become registered healthcare professionals. The pandemic has changed the way student paramedics learn, forcing them to adjust and adapt to studying in isolation and learning online. These dramatic changes to paramedic learning, although untimely and inconvenient, have presented several opportunities in developing professional skills such as adaption and improvisation; skills required by paramedics. Moreover, the experience student paramedics have gained through learning online may well assist them in performing online continuing professional development, a task required of the registered paramedic. COVID-19's impact on education encourages student paramedics to be more resourceful, creative, flexible and real problem solvers during this period of inconvenience and adversity. Student paramedics can safeguard their online journey by maintaining a schedule, staying engaged in the course material each week, being accountable with using goal setting strategies, and staying big picture focussed.

\section{Competing interests}

The authors declare no competing interests. Each author of this paper has completed a conflict of interest statement.

\section{References}

1. John Hopkins University Coronavirus Resource Centre. 2020. COVID-19 dashboard by the Centre for Systems Science and Engineering (CSSE). Available at: https:// coronavirus.jhu.edu/map.html

2. United Nations Educational, Scientific and Cultural Organisation. 2020. COVID-19 Educational disruption and response. Available at: https://en.unesco.org/covid19/ educationresponse

3. Miller RL, Rycek RF, Fritson K. The effects of high impact learning experiences on student engagement. Procedia Soc Behav Sci 2011;1:53-9. https://dx.doi.org/10.1016/j. sbspro.2011.03.050

4. Applegate R. The library is for studying: student preferences for study space. Journal of Academic Librarianship 2009;35:341-6. https://dx.doi.org/10.1016/j. acalib.2009.04.004

5. Alfehaid LS, Qotineh A, Alsuhebany N, Alharbi S, Almodaimegh $\mathrm{H}$. The perceptions and attitudes of undergraduate healthcare sciences students of feedback: a qualitative study. Health Professions Education 2018;4:18697. https://dx.doi.org/10.1016/j.hpe.2018.03.002

6. Bokhari N, Zafar M. Learning styles and approaches among medical education participants. J Educ Health Promot 2019;8:181. https://dx.doi.org/10.4103/jehp.jehp_95_19

7. Cheng DX. Students' sense of campus community: what it means, and what to do about It. NASPA Journal 2004;41:216-34. Available at: http://search.proquest.com/ docview/62078587/

8. Whitfield S, MacQuarrie A, Boyle M. Trained, ready but under-utilised: using student paramedics during a pandemic. Australasian Journal of Paramedicine 2020;17. https://doi.org/10.33151/ajp.17.799

9. Diehl K, Jansen C, Ishchanova K, Hilger-Kolb J. Loneliness at universities: determinants of emotional and social loneliness among students. Int J Environ Res Public Health 2018;15:1865. https://doi.org/10.3390/ijerph15091865

10. Donovan J. 2015. The importance of building online learning communities. Colorado State University. Available at: http://blog.online.colostate.edu/blog/online-education/theimportance-of-building-online-learning-communities/

11. Graduate Paramedic - ED [Internet]. Linkedln. 2020. Available at: www.linkedin.com/jobs/view/graduateparamedic-ed-at-svha-1815442022/?originalSubdomain=au [Accessed 24 April 2020]. 


\section{References (continued)}

12.Australian Health Practitioner Regulation Agency. National principles for clinical education during COVID-19 [Internet]. 2020. Available at: www.ahpra.gov.au/News/COVID-19/ National-principles-for-clinical-education-during-COVID-19. aspx [Accessed 22 April 2020].

13.Australian Government partnership with private health sector secures 30,000 hospital beds and 105,000 nurses and staff, to help fight COVID-19 pandemic [Internet]. Australian Government Department of Health. 2020. Available at: www.health.gov.au/ministers/the-hon-greghunt-mp/media/australian-government-partnership-with- private-health-sector-secures-30000-hospital-beds-and105000-nurses-and-staff-to-help-fight-covid-19-pandemic [Accessed 21 April 2020].

14. Queensland Government. 2020. Sixty new paramedics for Queensland to boost COVID-19 frontline response. Available at: http://statements.qld.gov. au/Statement/2020/4/15/sixty-new-paramedics-forqueensland-to-boost-covid19-frontline-response?fbclid=I wAR1AABrGER6cgEUwsfAGIRqE9PWIvaEivkpA_TIt|n6rioKLWJGWCceYe0

15. Victoria State Government. 2020. Boosting paramedic recruits on coronavirus frontline. Available at: www.premier. vic.gov.au/wp-content/uploads/2020/04/200414-BoostingParamedic-Recruits-On-Coronavirus-Frontline.pdf 